\title{
Beyond the trinity of gender, race, and class: Further exploring intersectionality in adult education
}

\author{
Cindy Hanson \\ University of Regina, Canada (cindy.hanson@uregina.ca) \\ Amber J. Fletcher \\ University of Regina, Canada (amber.fletcher@uregina.ca)
}

\begin{abstract}
Research exploring the gendered dimensions of adult learning has blossomed in the past two decades. Despite this trend, intersectional approaches in adult learning, research, and teaching remain limited primarily to the intersection of gender, race, and class. Meanwhile, intersectionality theories are more diverse, and include discussions of social structures, geographies, and histories that serve to build richer, nuanced descriptions of how privilege and oppression are experienced. Because the purpose of intersectionality is to understand how social identities and positions are constructed and to challenge the structures of power that oppress particular social groups, this approach is important for feminist and social justice educators. We, the Canadian authors of this manuscript, posit that adult education should move beyond intersectionality that focuses only on the trinity of gender + race + class to consider the other inequalities and the true complexities of representation and collective identities. By exploring literature in feminism, adult education, and intersectionality, we illustrate a gap at the core of adult education for social justice. We draw upon two examples of national research with and by the Canadian Research Institute for the Advancement of Women to illustrate how intersectionality is understood and works in practice.
\end{abstract}

Keywords: Feminism, inequity, intersectionality, social justice, solidarity.

ISSN 2000-7426

(c) 2021 The authors

https://creativecommons.org/licenses/by/4.0/

http://doi.org/10.3384/rela.2000-7426.3360

www.rela.ep.liu.se 


\section{Intersectionality and adult Education}

In the field of adult education, literature exploring intersectional approaches and practices (Hanson, 2019; Keskitalo-Foley \& Naskali, 2018; Merrill \& Fejes, 2018) has primarily focused on categories and intersections of gender, race, and class, an intersection sometimes referred to as the trinity (Dhamoon, 2011; Monture, 2007). Recent work edited by Merrill and Fejes (2018) acknowledged that intersections of gender, race, and class are examined in more recent adult education work; however, these categories of representation are frequently complicated by other factors - such as age, ability, location, and sexuality - which are less frequently addressed in the literature. In spite of this gap, there is recognition that intersectionality gives voice to nuanced dimensions of privilege and oppression as they are experienced and, thus, these dimensions are very much at the core of adult learning for social justice. A study by the European Association for Education of Adults (2019) posits that a challenge for adult learning in civil society remains the inclusion of underrepresented groups in adult nonformal learning processes. Because intersectional approaches consider multiple combinations of marginalization and (under)representation, they can help address such inclusion gaps. Ultimately, intersectional approaches are compatible with goals of social justice and equity, diversity, and inclusion as they are practiced within community-engaged adult education.

\footnotetext{
Intersectionality's objective is social justice. It is an orientation to research that focuses on revealing and responding to oppression and privilege in peoples' lives, by considering the effects of interpersonal interactions, and of socioeconomic and political structures. [...] Intersectionality can strengthen an analysis of the systemic power relations at work in peoples' lives, and help reveal allies who are working for reconciliation. (Levac et al., 2018, p. 25)
}

Intersectionality recognizes that people's experiences may be affected by several interacting systems of power that combine, reinforce or challenge each other. These systems construct people's experiences of marginalization and oppression, or of power and privilege. Intersectional approaches can provide a rich analysis of how communities or groups of people are marginalized and how inequitable structures or practices can be challenged. This paper first discusses how feminist theory and practice are foundational to intersectional approaches and, secondly, draws on two research projects to demonstrate the application of intersectionality in practice.

The first is a national study in Canada led by the Canadian Research Institute for the Advancement of Women (CRIAW), which aimed to identify and strengthen intersectional approaches to advocacy by women's organizations in Canada. The second is an interdisciplinary project designed to stimulate conversations and analysis about feminist intersectionality and knowledge systems from Indigenous learning and worldviews. Although the studies discussed in this manuscript emerge from Canadian contexts, they borrow from and lend to intersectional approaches also used in Europe (see, for example, the 2006 issue of European Journal for Women's Studies, or the special issue of the European Journal for Research on the Education and Learning of Adults (RELA, 2018). The two examples cited in this manuscript may additionally contribute to broader applications or insights into lived oppressions and power dynamics in the field of adult education. 


\section{Review of the literature}

Many feminist adult educators have already explored intersectional approachesparticularly as they relate to gender, race and class. Thus, we start this literature review by situating our work within the history and analysis of feminist thought and theory. This is followed by a closer examination of how adult education might further apply intersectional approaches and frameworks. Our goal is to suggest that the practice of adult education for social change - or for understanding how social structures impact and shift the lived experience of communities and learners - might be further enhanced by more attention to intersectionality.

\section{Feminist theory and intersectionality}

Variously defined as a concept, a theory, or a framework, intersectionality originated from Black feminist theory and activism, building on the work of Sojourner Truth and the Combahee River Collective (1977 [2007]; see also May, 2014) and finally named in the work of feminist legal scholar Kimberlé Crenshaw (1991). Intersectionality revises the analysis of gender in large part because 'feminist researchers have come to understand that the individual's social location as reflected in intersecting identities must be at the forefront in any investigation of gender' (Shields, 2008, p. 302). Collins (1990) termed these multiple identities and systems "interlocking" and posited a matrix of domination to ensure gender analysis was linked to other forms of power relations (Shields, 2008), further positing that agency was required to break the patterns of domination.

In an intersectional approach, social identities are complex and multidimensional that is, they can be sources of oppression, but also of privilege and in particular situations they may be both. An emphasis or bias may also be intentional or unconscious. For example, a White woman typically experiences racial privilege, but the white woman's sexual orientation, age, education, location (e.g., rural, urban), class, and employment status also affect how she is treated in particular situations. For this reason, intersectionality considers the contextual fluctuation of power while still recognizing that experiences and identities are linked to relatively stable systems of power like patriarchy, systemic racism, class, colonization, heteronormativity, and other deeply rooted social structures (Anthias, 2013; Fletcher, 2018). In other words, intersectionality is both an approach to power and to understanding social positions and structures.

Importantly, the fact that many analyses are structured to point out difference, not explain linkages, challenges efforts at intersectionality (Shields, 2008). Adult educators concerned with community development or citizenship, for example, not only need to conceptualize difference and structures that create it, but also develop strategies that highlight intersections of identity - something explored more fully in the examples following this literature review. Similarly, May (2014) noted that intersectionality itself is not merely focused on macro-level structures or micro-level identities; rather, it is linked and hybrid, both 'particular and universal in scope, though, from the stance of binary thinking, this can seem illogical, even nonsensical' (p. 96).

Feminist scholars of intersectionality have recognized the multi-level nature of intersecting oppressions, which exist at individual and structural levels simultaneously (Djoudi et al., 2016; Hanson, forthcoming; May, 2014; Winker \& Degele, 2011) and manifest discursively, ideologically, and materially (Fletcher, 2018). Importantly for adult educators, intersectionality offers us the opportunity to more fully embrace the complexities of lived experiences and thereby develop teaching and research practices that take those complexities into account, thus helping to address oppression in its various 
forms. Through intersectional approaches, individual experiences can be linked to their structural roots in oppressive systems. This may lead to building of coalitional politics (May, 2014).

Feminist intersectional practices challenge conventional norms and deepen analyses about how universal meta-narratives of truth can be interrupted. Denis (2008) analyzed how feminist intersectionality affected sociological thought, and in particular, how intersectionality exposed normative assumptions, even within feminist thought:

\begin{abstract}
Intersectional analysis involves the concurrent analyses of multiple, intersecting sources of subordination/oppression, and is based on the premise that the impact of a particular source of subordination may vary, depending on its combination with other potential sources of subordination (or of relative privilege). I argue that intersectional analysis can be understood as an outcome of applying the same type of critiques within feminism that (second wave) feminist sociologists had applied, in the 1960s and early 1970s... Their critique was that women were invisible in most sociological theorizing and analysis - an outcome of the (often implicit) assumption that men's experience was both universal and normative, except in (the primarily) affective relations within the family. (p. 677)
\end{abstract}

The description here is similar to how many educational programs or policies are explained without attention to experiences shaped by gender, race, age, immigration or citizenship status, location, (dis)ability, or sexuality; however, such constructed positions influence outcomes for individuals and collectives on a daily basis.

\title{
Adult education and intersectional frameworks
}

Broad constituencies of adult learners are discussed in adult education for social justice, and marginalization and inequity are common themes encountered in feminist and community-based policy and research work. There are however, limited adult education frameworks that interrogate lived inequalities (Groener, 2011; Rubenson \& Desjardins, 2009), despite the historical emphasis of feminist and adult education for social justice and collective community action (Groen \& Kawalilak, 2019). Shields's (2008) work for example, acknowledges the difficulties for researchers in making this shift "without falling back into the status quo approach' (p. 304). Her argument, to move into new understandings and identities by making the invisibility of intersectionality more visible, bodes well with adult education for social change. It suggests that intersectionality can further interrogate understanding how power is exerted, how inequality is experienced, and how solidarity with marginalized groups can be approached.

The aforementioned special issue of the RELA (volume 9) edited by Merrell and Fejes (2018) provided examples of how an intersectional analysis was framed in the European adult education literature. Similarly, an analysis of intersectionality in the Finnish journal, Aikuiskasvatus (adult education) between 2010-2016 provided important findings in terms of how intersectionality in adult education is framed around discourses of difference. The authors of this review, Keskitalo-Foley and Naskali (2018), argued for a more inter-categorical approach where categories of identity are used with intersectional theories and feminist pedagogies. This manuscript builds on that argument and provides examples in practice.

A rapid scoping of key adult education journals in North America, namely, Adult Education Quarterly, the Canadian Journal for the Study of Adult Education, and Adult Learning yielded similar results when the search terms intersectional and adult education/learning were used. The most frequent form of intersectionality discussed in these journals was race and gender; this finding is consistent with other literature on 
intersectionality which demonstrates that the most common identity variables considered are gender, race, and class (Yuval-Davis, 2006). One title explored the intersection of race and gender, with reference to these factors as the key components of intersectionality introduced by Kimberlé Crenshaw in 1989 (Jean-Marie et al., 2009). Crenshaw (1997) challenged single-identity analyses for women, noting that race and gender interlocked in her life as a Black woman. While the concepts of gender, race, and class are central to the discussions and analysis on intersectionality, limiting discussion to gender plus race or class (or one or two other components of identity) may omit other attributes and associated narratives that frame and construct complex lived experiences.

The European Society for the Research of Education for Adults (ESREA) gender network highlighted intersectionality at its 2017 conference entitled, Gender - Diversity - Intersectionality. (New) Theories and Policies in Adult Education. Like the book by the same name (Endepohls-Ulpe \& Ostrouch-Kaminska, 2019), the majority of presentations highlighted gender and one or two other aspects of diverse representations. Clover, Butterwick and Collins (2016) extended the understanding of intersectionality in their book, Women, Adult Education, and Leadership in Canada, which provides a unique decolonizing perspective addressing women and leadership in adult education; however, they were critiqued for lack of attention to LGBTQ issues (Huron, 2017).

In a ten-year review of themes and issues in the journal Adult Learning (Cherrstrom, Robbins, \& Bixby, 2017), the sole application of the word intersection was to illustrate the noun intersection as a link between two fields - adult learning and higher education. Similarly, the theme of diversity appears more often in the final years of their ten-year study (leading up to 2015), but the authors' uptake of diversity does not critically interrogate how different components of identity or representation intersect to construct particular experiences of marginalization and oppression, power and privilege-whether unconsciously and/or intentionally. Intersectionality approaches explore those themes as fluid and performative, but emphasize that experiences are also linked to broader systems of power (Smooth, 2013).

Leaving out other categories or complexities beyond the trinity-gender, race, and class - can make the outcomes of research less comprehensive. Recently for example, a study reported in Adult Learning on acculturation experiences of Syrian Muslim refugee women in the US (Ugurel Kamisli, 2020) demonstrated a more complex intersection of identities including nationality, religion, gender, and refugee status, thus illustrating how adult learning is bound by constraints beyond the trinity. The use of gender plus race or class is undoubtedly the most common way intersectional issues are understood, in part because there are few frameworks in adult education from which the more complex analyses can emerge.

\section{Frameworks for an Intersectional Analysis}

Intersectional analyses demonstrate how complex experiences of oppression that occur at the intersection of multiple aspects of identity - for example, gender, race, class, ability, age, belief systems, language, sexuality, and location - are influenced by and combine with structures of inequality and power. Put more simply, if equality is possible through structural change processes, then categories matter - for example, painting all women as equal when we know that poor, older, or rural women are less likely to participate in adult education or, similarly, ethnic minorities, migrants, Indigenous or transgender persons may have life experiences very different from each other and from those of college, group, or community leaders (Hanson, forthcoming). None of the categories are homogeneous 
and differences or linkages within each can identify additional locations for structural analysis.

Recently, institutional efforts to apply more intersectional approaches in policy and program development have become evident. For example, national governments in Europe use additive (multiple) discrimination (or similar) terms, including discrimination as synergistic (Fredman, 2016), and federally, Canada uses Gender-Based Analysis Plus $(\mathrm{GBA}+)$ as a method to aid government departments in analyzing the impact of gender and intersecting forms of identity discrimination on policies, programs, and projects (Status of Women Canada, 2018). Although challenges remain in fully implementing GBA+ across government departments and initiatives in Canada (Wright, 2019), an obvious advantage is increased recognition that all policies and programs interact with inequality in the social body.

Intersectional frameworks attempt to provide a more complex analysis that explores the diversity and complexity of lived experience. Such frameworks help to identify the structures of oppression or advantage, the kinds of discrimination these structures construct or co-construct; and how aspects of social position, history or identity are impacted and a starting point for making essential changes. A feminist intersectional analysis puts women at the centre of this framework in order to make policies, services and programs more accessible and inclusive for all people, while ensuring that the feminist origins and aims are not lost (Manning, 2014). According to CRIAW, 'The goal of a feminist intersectional analysis is to understand power relations and systems of power that create barriers to women's equality so we can work to remove those barriers and redistribute power equitably' (CRIAW, 2019, p. 4).

The following diagram, originally developed by the Canadian Research Institute for the Advancement of Women (CRIAW), demonstrates components of a feminist intersectional framework:

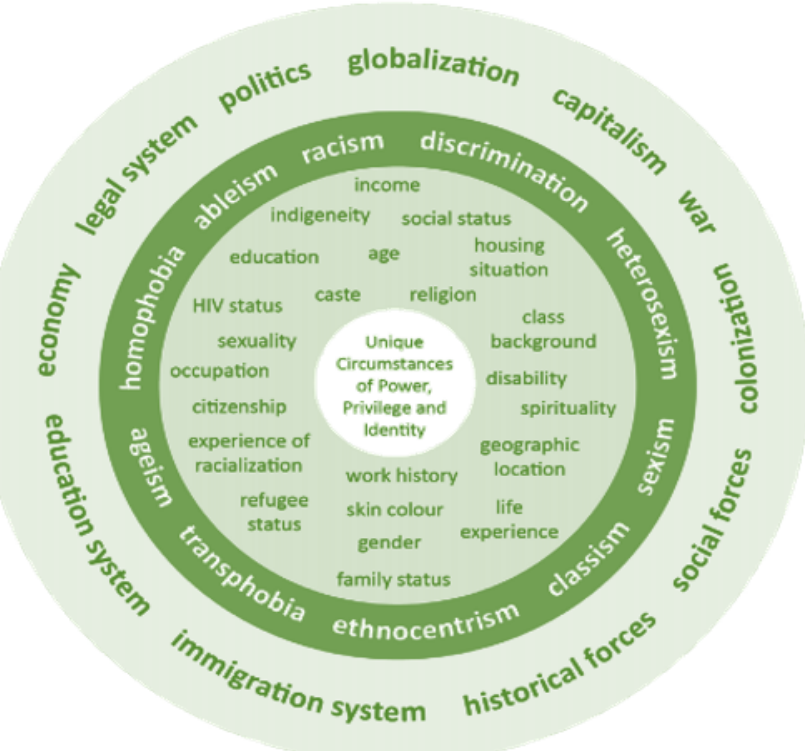

Diagram provided with permission of CRIAW

In this nested intersectionality diagram, the innermost circle is meant to represent an individual's particular circumstances; the second circle, aspects of identity; the third indicates various types of discrimination; and the outermost circle shows broader social forces and structures that cause and construct experiences of marginalization and 
exclusion (Simpson, 2009). This tool has been widely used and adapted and, more recently, critiqued for what it does/does not include (Hanson, forthcoming).

The key challenge in an intersectional analysis is to consider the multiple, intersecting forms of oppression, power and disadvantage experienced by certain groups. Further, the inclusion of gender identities that go beyond binaries of men and women (for example transgender or non-conforming identities) bring to light how the very notion of gender or sex as a binary can create a structure of oppression. Such structural barriers have socio-political and personal consequences (Hanson, forthcoming).

The following sections present two examples of efforts to advance intersectionality in practice; both were conducted by CRIAW and affiliated researchers. The first example is a Canadian study of women's organizations' capacity to engage in intersectional advocacy. The second is an attempt to synthesize feminist intersectionality and Indigenous ways of knowing in order to advance reconciliation and epistemic pluralism. Both examples reveal current challenges in implementing intersectional approaches, while simultaneously demonstrating the value of intersectional analysis for highlighting both experiential and systemic forms of inequality.

\section{Example one:}

\section{Building capacity for intersectional advocacy on women's issues}

CRIAW is a not-for-profit, member-based women's organization with 45 years of experience doing feminist research. ${ }^{1}$ As a national institute focused on producing publicly accessible feminist analysis, CRIAW is concerned with structural inequality and the role patriarchy plays in shaping women's diverse experiences (CRIAW, 2019). The organization takes a feminist intersectional stance that centres women in their multiple diversities and explores how different identity categories, separately, together and combined, influence women's lives.

CRIAW recently completed a five-year project (funded originally by Status of Women Canada; in 2018 renamed Women and Gender Equality Canada) to examine the capacity of Canadian women's organizations to do intersectional advocacy work. In the study, women's organizations were invited to respond to a survey inquiring about their current understandings of intersectionality and its application in practice. In a second phase, organizations were invited to engage in a series of regional focus groups aimed at deepening collective understandings of what intersectionality means in theory and practice. The third phase involved using that knowledge to identify how to build inclusive networks that strengthen collective capacity for advocacy on women's issues. The study produced a series of publicly accessible, no-cost resources to support organizations in their intersectional practice. Although the study focused on women's organizations, the question more broadly queried the role of intersectionality in building social movements.

We, the authors of this manuscript, are CRIAW members and have both served as the organization's President in recent years. We served as co-applicants on the application for the study's behavioural ethics approval through our university's Research Ethics Board. We worked collaboratively on the methodological design and participated in several stages of the data collection process; we also served on the five-person advisory committee that oversaw the process from design phase to knowledge mobilization. 


\section{Study methodology}

CRIAW's study began with an environmental scan, which produced a list of over 600 diverse women's organizations operating at the local, provincial, and national levels across Canada. The list was compiled from publicly available sources, existing lists, internet and social media searches and suggestions from CRIAW members. The list was organized into a matrix identifying each organization by province or region, official language of operation (English or French), and main constituency and issue(s) in order to select a diverse sample of women's organizations across the country. From the original list, 100 women's organizations were selected to complete an on-line survey in English or French; 50 organizations responded (33 in English, 17 in French). Next, CRIAW held five regional discussion groups (i.e., focus groups) across Canada, which were attended by representatives of 34 organizations in total. These data collection efforts were supplemented by key stakeholder interviews. After the data were analyzed, CRIAW staff and the advisory group worked collectively to develop a webinar and toolkit to support organizations' efforts at intersectional advocacy.

\section{Results: Challenges of and lessons in intersectional advocacy}

The results of the study demonstrated that women's organizations have an overwhelming interest in intersectionality, both in theory and in practice. Survey data showed half of the responding organizations had a strong grasp of intersectionality as a concept, while a few had virtually none. Respondents' definitions often emphasized the intersection of gender, race, and class but, notably, survey responses frequently went beyond the trinity to identify additional intersecting dimensions, such as sexuality and citizenship. For example, one responding organization noted that:

Intersectionality recognizes that identities and social roles related to gender, race, ethnicity, socio-economic class, age, immigrant or refugee status, mental and physical abilities, religion, sexuality, family and other statuses intersect. (survey respondent)

Despite strong interest, the application of intersectionality, as noted by the participating organizations, was hampered by structural barriers, particularly resource constraints. Women's organizations spoke frequently about having too much work and too few resources, which negatively affected their ability to engage in intersectional advocacy. Most of the participating women's organizations reported having very few paid staff members. Almost all of those responding in French (93\%) and almost half (49\%) of those responding in English reported having five or fewer staff members. Almost two-thirds $(63 \%)$ of English organizations employed ten or fewer staff members. The results indicate that capacity issues are inhibiting organizations' ability to do intersectional work.

Despite these challenges, many of the women's organizations said they would like to do more intersectional advocacy work. In order to do this work, organizations reported a need for 1) more staff or full-time advocates; 2) more financial and human resources; 3 ) expanded ability to advocate on behalf of groups that are currently not served and on issues where there is not currently a gender lens; and, 4) coordinated advocacy with other equality-seeking groups and more opportunities to network, educate, and provide resources to women. Half of the responding organizations ( 12 of 23 responses) mentioned training as the most helpful way for the organizations to build capacity for intersectional work. The type of training they desired included webinars, workshops, training modules, professional development, and engaging with outside resource people to expand 
knowledge. A few did not want online webinars or online tools, saying, "they do not facilitate dialogue" and instead named preferences for interactive and in-person training.

The organizations said the services women needed were often not available, that research and policy work frequently went undone, and that tools for advocacy were not well developed. They reported no time for an intersectional analysis of issues or outreach and input from the surrounding community because they did not have the capacity. One survey participant said:

With only one employee, [the organization] struggles to meet the needs regarding advocacy. A good chunk of the ED's [Executive Director's] time is spent reporting to funders, coordinating projects, and searching for new streams of funding. Unless advocacy is built into a project there's not always time to address it.

The results of this study illustrate that the lack of core resources for women's organizations is the primary barrier in taking an intersectional approach to their work. Weak capacity, unstable funding and inadequate resources to do advocacy work means women's organizations cannot do the necessary research and policy work or tool development required to build strong movements. Despite capacity gaps, the commitment to equality and to the women's movement keeps these organizations doing their work, albeit with varied levels of understanding about intersectionality and how to implement it.

On provincial level, we advocate for improved educational curriculum, changes to family law act, improved services for victims of violence, improvements in mental health and substance use services, for the development of a taskforce on violence against women and girls, improved services for LGBTQ+ populations, for the establishment of a municipal committee to address social issues, for the establishment of additional women's centres in areas of the province that require services. (Survey participant)

Other non-governmental or community-based groups who participated mirrored this sentiment. Because of adult education's relationship to non-formal learning in social movements (English \& Mayo, 2012; Holford, 1995), studies of organizing, resourcing, and sustaining community capacity are of ongoing interest to the field. Moreover, Irving and English (2011) add that a lack of resources can lead to internal conflict within the organizations themselves, and this can weaken the movements.

Ultimately, the data collected by CRIAW will help build capacity for intersectional feminist advocacy resources amongst Canadian equity-seeking organizations. In the current neoliberal context of Canadian and many European institutions and policymaking (Arat-Koç, 2012; Paterson, 2010), this knowledge can serve to improve the narrow gaze of binary or one-dimensional thinking. There is a role for educators, policymakers, and activists in efforts to advance intersectional thinking; however, the key challenge is best summed up by the survey participant who said, '[Women's organizations] need more funding to be able to effectively make change through advocacy.'

The impacts of social inequities are ongoing pieces in the history of adult education in Canada (English, 2016). Yet, an intersectional approach that examines sustained or even temporary experiences of exclusion and privilege (Levac \& Denis, 2019) is rare. Funding is recognized as necessary for doing advocacy work, but so too are tools and capacity to ensure the work is inclusive of diverse groups. The next example explores inclusivity among diverse epistemic groups. 


\section{Example two:}

\section{Linking epistemic knowledges and adult education}

The second example is a knowledge synthesis project. Knowledge synthesis is a systemic analysis of existing evidence based on prior knowledge and study. In health sciences it is commonly used to accumulate evidence systematically in order to draw out new conclusions or solutions from existing research (Grimshaw, 2020).

The project, Learning across Indigenous and Western knowledge systems and intersectionality: Reconciling social science research approaches was a funded knowledge synthesis grant ${ }^{2}$ - thus, it was a structured and a systematic attempt to gather existing academic and community-based materials, and synthesize the materials looking for evidence-based points of convergence as they existed in relation to feminist intersectionality and Indigenous knowledge. The project sought ways of framing two knowledge systems - intersectionality and Indigenous - as complementary, and possibly as collaborative:

\footnotetext{
Some knowledges have long been marginalized within Western scientific traditions as well. The knowledges of women, queer, disabled, and racialized knowledge holders are examples. One of the responses to this exclusion is the theoretical idea and practice of intersectionality, which contends that varying forms of oppression are interrelated, interactive, and co-constitutive. (Levac et al., 2018, p. 6)
}

Through a coding of the 27 original principles that emerged from the data (literature and discussions with key informants including knowledge keepers), the research team were able to summarize seven principles that were linked to intersectionality, non-Western, and Indigenous epistemologies. The seven principles were reciprocity, relationality, reflexivity, respect, reverence, responsivity, and responsibility (Levac et al., 2018). Importantly, the analysis illustrated both points of convergence and of tension between the models.

Epistemological difference is seldom central to in an intersectional analysis, but it does illustrate deep-seated points of potential contention and/or possible collaboration, even solidarity. Using intersectional frameworks provides insight into these points of diversity that would not otherwise be viewed as compatible. As Shields (2008) argued, intersectionality points out linkages, not just differences. In the field of adult education, linkages, solidarities, and participatory practices all remain central to work in communities, in organizations, and in social movements. Such solidarity and participatory practices can, in turn, help to reveal and build collective challenges to existing power and privilege; thus, intersectional analyses and adult education can be mutually reinforcing.

Learning and sharing how intersectional approaches might influence our methods of research and engagement, our pedagogies in communities or classrooms, and our ways of building social movements is timely. For example, the field of adult learning has tended to view social movements in adult education from the perspective of a divide between the global North and the global South (Mayo \& English, 2012), likely due to the influence of Freire (1970) and emancipatory possibilities/oppression, but this knowledge synthesis project demonstrated that there may be other ways of building and linking ideas.

In addition to the factors already mentioned, epistemic pluralism opens conversations for multiple perspectives. For example, recent patterns in migration to Europe can open conversations about policy and practice issues in new ways that are not bound by Western constructs or epistemologies and include diverse histories and geographies. Adult education, especially as it relates to community engagement, aims to 
create equity, collaboration, and solidarity, and more recently, efforts to decolonize approaches to learning (Hanson, 2019; Hanson \& Jaffe, 2021). Thus, engaging with intersectional approaches such as those described in the Levac et. al. (2018) project can build pathways for knowledge and epistemic solidarities while challenging hegemony.

\section{Conclusion: From invisibility to solidarity}

Given the growing importance of representational politics and the need to continue traditions of building movements, democratic communities, classrooms and collective histories, expanding the influence of intersectionality in research and pedagogical practices offers an opportunity for deepening our practice. Ideologies of superiority and privilege through gender, race, class, sexuality, age, location - as well as associated forms of over-representation or under-representation - are (re)constructed by institutional and social structures; for example, the locations of our work, our history, and by the curricula and the examples we choose. The absence of certain examples can reinforce oppression. A structural analysis demonstrates that how power is exercised in teaching and research can support possibilities for transformation and solidarity. Conversely, refusing to make such efforts can lead to further homogenization and hegemony.

The development of tools such as CRIAW's intersectionality framework, or synthesis research that connects epistemic knowledges, provide examples for how community organizations and adult educators can analyse categories beyond gender, race, and class and demonstrate that none of the categories are homogeneous. Further making the public education tools freely available, such as those developed by CRIAW in both of our examples, can support organizations dealing with under-funding and resource challenges in order to bring intersectionality into their work.

Importantly for the field of feminist/adult learning, intersectional frameworks provide a conceptual, theoretical, and discursive way to analyse the intersecting attributes encountered in our practices within communities, organizations, and learning groups. An intersectional approach also creates space for epistemic pluralism and highlights complex experiences of inequality, potentially leading to more inclusive educational practices and solidarity-building. Within the realm of nonformal and informal learning, these practices remain key components of liberatory values in adult education (English \& Mayo, 2012). If adult education - particularly in communities, and in nonformal education or social movement contexts - aims to create conditions for change and pedagogies of solidarity (Freire, Araújo Freire, \& Ferreira de Oliveira, 2014), then intersectional frameworks are a much-needed resource.

\section{Notes}

\footnotetext{
${ }^{1}$ Additional information about CRIAW, along with free resources on feminist and intersectionality topics, can be found at: https://www.criaw-icref.ca

${ }^{2}$ Funding for this knowledge synthesis grant was provided by the Social Sciences and Humanities Research Council of Canada (SSHRC).
}

\section{Acknowledgements}

The authors acknowledge the Canadian Research Institute for the Advancement of Women for the use of the intersectionality framework graphic, the literature inputs, and 
most importantly, for the research work on intersectionality which provided examples for this paper.

\section{References}

Anthias, F. (2013). Intersectional what? Social divisions, intersectionality and levels of analysis. Ethnicities, 13(1), 3-19. https://doi.org/10.1177/1468796812463547

Arat-Koç, S. (2012). Invisibilized, individualized, and culturalized: Paradoxical invisibility and hypervisibility of gender in policy making and policy discourse in neoliberal Canada. Canadian Woman Studies/les cahiers de la femme, 29(3), 6-18.

Cherrstrom, C. A., Robbins, S. E., \& Bixby, J. (2017). 10 years of adult learning: Content analysis of an academic journal. Adult Learning, 28(1), 3-11. https://doi.org/10.1177/1045159516664320

Clover, D. E., Butterwick, S. J., \& Collins, L. (Eds.) (2016). Women, adult education, and leadership in Canada: Inspiration, passion, and commitment. Thompson Educational Publishing.

Collins, P.H. (1990). Black feminist thought: Knowledge, consciousness, and the politics of empowerment. Unwin Hyman.

Combahee River Collective. (2007). A Black feminist statement (1977). In E. B. Freedman (Ed.), The essential feminist reader (pp. 325-330). The Modern Library.

Crenshaw, K. (1991). Mapping the margins: Intersectionality, identity politics, and violence against women of color. Stanford Law Review, 43(6), 1241-1299. https://doi.org/10.2307/1229039

Crenshaw, K. (1997). Intersectionality and identity politics: Learning from violence against women of colour. In M. L. Shanley \& U. Narayan (Eds.), Reconstructing political theory: Feminist perspectives (pp. 178-193). Pennsylvania State University Press.

CRIAW. (2019). Feminist intersectionality: A primer. Ottawa: CRIAW.

Denis, A. (2008). Review essay: Intersectional analysis: A contribution of feminism to sociology. International Sociology, 23(5), 677-694. https://doi.org/10.1177/0268580908094468

Dhamoon, R.K. 2011. Considerations on mainstreaming intersectionality. Political Research Quarterly, 64(1), 230-43. https://doi.org/10.1177/1065912910379227

Djoudi, H., Locatelli, B., Vaast, C., Asher, K., Brockhaus, M., \& Sijapati, B. B. (2016). Beyond dichotomies: Gender and intersecting inequalities in climate change studies. Ambio, 45(S3), 248262. https://doi.org/10.1007/s13280-016-0825-2

Endepohls-Ulpe, M., \& Ostrouch-Kamińska, J. (Eds.). (2019). Gender - diversity - intersectionality: (New) perspectives in adult education. Waxmann Verlag GmbH.

English, L., \& Mayo, P. (2012). Adult education and social movements: Perspectives from Freire and beyond. Educazione Democratica, 3, 1-31. https://www.um.edu.mt/library/oar/handle/123456789/1481

English, L.M. (2016). Critical and creative transformative learning: "Longing for the sea" in feminist non-profit organizations. In D. E. Clover, S. Butterwick, \& L. Collins (Eds.), Women, adult education and leadership in Canada: Inspiration, passion and commitment (pp. 297-306). Thompson Educational Publishing.

European Association for Education of Adults. (2019). Adult education in Europe: A civil society view. Brussels: European Association for the Education of Adults. https://issuu.com/eaeapublications/docs/country_reports 2019 layout

Fredman, S. (2016, May). Intersectional discrimination in EU gender equality and non-discrimination law. Technical report. Luxembourg: Office of European Union.

Fletcher, A. J. (2018). More than women and men: A framework for gender and intersectionality research on environmental crisis and conflict. In C. Fröhlich, G. Gioli, R. Cremades, \& H. Myrttinen (Eds.), Water security across the gender divide (pp. 35-58). Springer International Publishing.

Freire, P. (1970). Pedagogy of the oppressed. Continuum.

Freire, P., Araújo Freire, A.M., \& Ferreira de Oliveira, W. (2014). Pedagogy of solidarity. Left Coast Press.

Grimshaw, J. (2020). A guide to knowledge synthesis: A knowledge synthesis chapter. Canadian Institutes of Health Research. https://cihr-irsc.gc.ca/e/41382.html

Groen, J., \& Kawalilak, C. (2019). Reflections on the adult education professoriate in Canada. Education Sciences, 9(1) 43. https://www.semanticscholar.org/paper/Reflections-on-the-Adult-EducationProfessoriate-in-Groen-Kawalilak/026ff31c6ff9a49622c916147aa97c6eeffe0da1 
Groener, Zelda (2011). "Adult education, globalisation and inequality in South Africa. Searching for new analytical frameworks," Adult Education Research Conference.

https://newprairiepress.org/aerc/2011/papers/41

Hanson, C. (2019). Canada's Indian Residential Schools, intersectionality and decolonizing adult education. In Endepohls-Ulpe, M. \& Ostrouch-Kamińska, J. (Eds.) Gender-diversity intersectionality: (New) perspectives in adult education (pp. 139-148). Germany: Waxmann Verlag GmbH.

Hanson, C. (forthcoming). The Role of Citizenship Education in Reducing Gender Inequalities. Commissioned paper. Background paper for fifth GRALE 5, UNESCO report.

Hanson, C., \& Jaffe, J. (2021). Decolonizing adult and continuing education: Critical pathways and practices. In T.S. Rocco, M.C. Smith, R.C Mizzi, L. Merriweather, \& J. Hawley (Eds.). Handbook of adult and continuing education. (pp. 341-349). Stylus Pub.

Holford J. (1995). Why social movements matter: Adult education theory, cognitive praxis and the creation of knowledge. Adult Education Quarterly, 45(2), 95-111.

Huron, M. (2017). Review of Women, Adult Education, and Leadership in Canada. Canadian Journal of Educational Administration and Policy, 182, 26-29.

Irving, C. J., \& English, L. M. (2011). Community in cyberspace: Gender, social movement learning, and the internet. Adult Education Quarterly, 61(3), 262-278. https://doi.org/10.1177/0741713610380448

Jean-Marie, G., Williams, V. A., \& Sherman, S. L. (2009). Black women's leadership experiences: Examining the intersectionality of race and gender. Advances in Developing Human Resources, 11(5), 562-581. https://doi.org/10.1177/1523422309351836

Keskitalo-Foley, S., \& Naskali, P. (2018). Intersectionality in Finnish adult education research: Insights from the journal Aikuiskasvatus 2010-2016. European Journal for Research on the Education and Learning of Adults, 9(1), 13-27. http://www.rela.ep.liu.se/issues/10.3384_rela.20007426.201891/9103/rela_9103.pdf

Levac, L. \& Denis, A.B. (2019). Combining feminist intersectional and community-engaged research commitments: Adaptations for scoping reviews and secondary analyses of national data sets. Gateways: International Journal of Community Research and Engagement, 12(1), 1-19. https://doi.org/10.5130/ijcre.v12i1.6193

Levac, L., Steinstra, D. McMurtry, L., Hanson, C., Blaikie, G., \& Mucine, D. (2018). Learning across Indigenous and Western knowledge systems and intersectionality: Reconciling research approaches. SSHRC Knowledge Synthesis Report. University of Guelph. http://www.criawicref.ca/product-print.php?id_product $=64$

Manning, S. (2014). Fem-North Net fact sheet. Feminist intersectional policy analysis: Resource development and extraction. Ottawa: CRIAW. http://fnn.criawicref.ca/images/userfiles/files/FIPAFramework.pdf

May, V. M. (2014). "Speaking into the void?” Intersectionality critiques and epistemic backlash. Hypatia, 29(1), 94-112. https://doi.org/10.1111/hypa.12060

Merrill, B., \& Fejes. A. (2018). Editorial: Intersectionality and adult education. European Journal for Research on the Education and Learning of Adults, 9(1), 7-11.

Monture, P.A. (2007). Racing and erasing: Law and gender in white settler societies. In S. P. Hier \& B. S. Bolaria (Eds.), Race \& racism in 21st century Canada: Continuity, complexity, and change (pp. 197-212). Broadview.

Paterson, S. (2010). What's the problem with gender-based analysis? Gender mainstreaming policy and practice in Canada. Canadian Public Administration, 53(3), 395-416. https://doi.org/10.1111/j.1754-7121.2010.00134.x

Rubenson, K., \& Desjardins. (2009). The impact of welfare state regimes on barriers to participation in adult education: A bounded agency model. Adult Education Quarterly, 59(3), 187-207. https://doi.org/10.1177/0741713609331548

Shields, S. A. (2008). Gender: An intersectionality perspective. Sex Roles, 59(5-6), 301311.https://doi.org/10.1007/s11199-008-9501-8

Simpson, J. (2009). Everyone belongs: A toolkit for applying intersectionality. Ottawa: Canadian Research Institute for the Advancement of Women (CRIAW).

Smooth, W. G. (2013). Intersectionality from theoretical framework to policy intervention. In A. R. Wilson (Ed.), Situating intersectionality: Politics, policy, and power (pp. 11-41). Palgrave Macmillan. https://doi.org/10.1057/9781137025135_2

Status of Women Canada (2018). What is GBA Plus?. https://cfc-swc.gc.ca/gba-acs/index-en.html 
Ugurel Kamisli, M. (2020). Acculturation experiences of Syrian Muslim refugee women in the United States: Intersectionality of nationality, religion, gender, and refugee status. Adult Learning. https://doi.org/10.1177/1045159520962852

Winker, G., \& Degele, N. (2011). Intersectionality as multi-level analysis: Dealing with social inequality. European Journal of Women's Studies, 18(1), 51-66. https://doi.org/10.1177/1350506810386084

Wright, T. (2019, February 2). Internal docs show many federal departments not meeting gender analysis targets. The Star. Retrieved November 18, 2020, from https://www.thestar.com/news/canada/2019/02/02/internal-docs-show-many-federal-departmentsnot-meeting-gender-analysis-targets.html

Yuval-Davis, N. (2006). Intersectionality and feminist politics. The European Journal of Women's Studies, 13(3), 193-209. https://doi.org/10.1177/1350506806065752 